\title{
SUSTENTABILIDADE ECONÔMICA E AMBIENTAL: UM IDEAL DA SOCIEDADE INTERNACIONAL*
}

\author{
ECONOMIC AND AMBIENT SUSTAINABILITY: \\ AN IDEAL OF THE INTERNATIONAL SOCIETY
}

\author{
Prof ${ }^{\circ}$. Ms. Ana Claudia Duarte Pinheiro" \\ Prof ${ }^{\circ}$. Dr ${ }^{\circ}$. Marlene Kempfer Bassoli
}

\begin{abstract}
Resumo: A incorporação do tema ambiental por organismos internacionais e blocos regionais, ao longo das últimas décadas do século XX, demonstra uma lenta preocupação com o caminho do desenvolvimento sócio-econômico sustentável. O processo de desenvolvimento, que se consolidou a partir do modo de produção capitalista, exerceu influência sobre a sociedade de um modo geral. Um modelo econômico de efeito globalizante, trouxe à tona uma nova rede de relações, com reflexos, inclusive, nas estruturas políticas dos Estados. Assim, entre as necessárias preocupações, diante das mudanças, está a incorporação de valores relacionados ao meio ambiente para alcançar o desenvolvimento sustentável, ou seja, desenvolvimento econômico com preservação do meio ambiente e justiça social. Diante da transnacionalidade da questão ambiental e para alcançar tal objetivo, é fundamental despertar para a consciência do caminho da harmonização legislativa.
\end{abstract}

Palavras-chave: Meio-ambiente, Organização Mundial do Comércio, União Européia, Harmonização Legislativa, MERCOSUL, Valores Econômicos, Desenvolvimento Austentável e Axiológicos, Progresso e Justiça Social.

\footnotetext{
"Artigo extraído da Dissertação de Mestrado, apresentada ao Programa de PósGraduação Stricto Sensu da Universidade Estadual de Londrina, de autoria do primeiro sob a orientação do segundo.

Mestre em Direito Negocial pela Universidade Estadual de Londrina. Professora de Direito Financeiro na Universidade Estadual de Londrina.

Doutora em Direito do Estado-Direito Tributário, pela PUC-SP. Professora dos programas de Mestrado em Direito da Universidade Estadual de Londrina-UEL/PR e da Universidade de Marília-UNIMAR/SP.
} 


\begin{abstract}
The Incorporation of the environmental issue by international offices and regional blocks in the last decades, has demonstrated a growing preoccupation with the road to sustainable socio-economic development. The contemporary development process, consolidated by the capitalist production model, has exercised great influence on society in general. This globalized economic model gave rise to a new network of relations which have affected the political structures of the States. Thus, among the many concerns involving these changes is the incorporation of environmental values to reach sustainable development, i.e., to promote economic development taking into account environment protection and social justice. In face of the transnationality of the issue and the importance of the objective at hand, it is fundamental to raise people's awareness of the legal harmonization issue.
\end{abstract}

Key words: Environment. World Trade Organization, European Union, MERCOSUR, Legal Harmonization, Sustainable Development, Economic and Axiological Values, Progress and Social Justice.

\title{
1 INTRODUÇÃO
}

Ao longo das últimas décadas, significativas transformações vêm ocorrendo em âmbito de políticas públicas internas, voltadas à proteção do meio ambiente, tanto no que se refere à preservação, quanto em relação à sua recuperação.

Tal preocupação está presente em Organismos internacionais e blocos regionais, demonstrando, mediante propostas e projetos, a importância da implementação de ações direcionadas ao meio ambiente e que se expandem mundo afora.

A viabilização do processo desenvolvimentista determinada ao longo do século XX e que se consolidou como um novo modo de produção denominado capitalismo influenciou culturas e sociedades. Os últimos cinqüenta anos foram determinantes para uma nova rede de relações que provocaram significativas mudanças nas estruturas políticas dos Estados em conseqüência de um novo modelo econômico de efeito globalizante.

Evidenciou-se a aproximação entre os Estados com a formação de blocos regionais e adesão a organismos multilaterais. A integração tem se revelado essencial tanto para os países de frágil economia, quanto para os países desenvolvidos. A globalização econômica expressa a confirmação das transformações alcançadas pelo mundo contemporâneo e que, se proporcionou avanços tecnológicos, o mesmo não aconteceu no plano social, ambiental e político. 
A questão ambiental emerge nesta rede de relações. Trata-se de um dos valores mais importantes para toda a humanidade e que se evidencia a cada vez em que são colocados em confronto os interesses da sociedade internacional, tanto aos mais desenvolvidos, quanto aos que se encontram em fase de desenvolvimento.

A existência humana implica em respeito às condições que lhe permitem uma sobrevivência digna. Certamente que tais condições não se resumem unicamente à questão econômica. Importa ao processo de globalização, valores que exprimem os interesses da sociedade como um todo. O meio ambiente é um dos que mais expressam a convergência de tais interesses, ainda que, por diversas oportunidades, se evidenciem antagonismos, no que diz respeito à exploração dos recursos ambientais.

Apresenta-se nesta pesquisa um relato da importância dada ao tema ambiental, em nível internacional. Primeiramente demonstra-se a abordagem oferecida pela Organização Mundial do Comércio. Na seqüência, são apresentadas as ações propostas pela União Européia e o MERCOSUL, no intuito de demonstrar que as questões relacionadas ao meio ambiente são reveladas como preocupações constantes, embora poucos avanços se consolidaram..

Ao final uma abordagem sobre a questão da harmonização legislativa na formação e consolidação de blocos regionais em temas fundamentais, entre eles, o do meio ambiente e desta forma caminhar para o desenvolvimento sustentável.

\section{ORGANIZAÇÃO MUNDIAL DO COMÉRCIO - OMC}

O conceito de desenvolvimento sustentável, reconhecido a partir da realização da ECO-92 e incorporado no GATT-94 e posteriormente pela OMC, considerou a importância do tema para a Sociedade Internacional. Sidney Amaral Cardoso (2003, p. 275), ao explanar sobre o documento de constituição da OMC, expõe:

Segundo o documento, as relações entre os membros no campo do comércio e de esforços econômicos deveriam ser conduzidos com vistas a aumentar os padrões de vida, assegurar o pleno emprego, permitindo o uso ótimo dos recursos mundiais em consonância com os objetivos do desenvolvimento sustentável, buscando tanto proteger e preservar o meio 
ambiente quanto intensificar os meios para fazê-lo de uma maneira consistente com as respectivas necessidades e preocupações em diferentes níveis de desenvolvimento econômico.

Com o objetivo essencialmente econômico - nesta era de abertura comercial e liberalização dos mercados - o alerta da OMC não discrepa em sua constituição, da condição de manter sua influência sobre o comércio mundial, estabelecendo suas regras específicas, sem descuidar de temas relevantes para toda a humanidade, como é o caso do meio ambiente, que angariou expressivo valor a partir da Conferência de Estocolmo, consolidando-se definitivamente com a realização da ECO-92.

Evidenciou-se em 1995 a importância - ainda que timidamente demonstrada - cada vez maior dada às questões relativas à natureza e ecologia, quando o Conselho Geral da OMC criou o Comitê sobre Comércio e Meio Ambiente - CTE, com o objetivo de "estabelecer uma relação construtiva entre o comércio e preocupações ambientais”(CARDOSO, 2003, p. 275).

Mesmo assim sua atuação é limitada por diversos motivos, dentre os quais se destacam questões de natureza ideológica - o entendimento de que a liberalização comercial resultará em benefícios ao meio ambiente, ao comércio e ao desenvolvimento - o que reflete o antagonismo entre os interesses comerciais e ambientais. Suas atribuições são apresentadas por Sidney Amaral Cardoso (2003, p. 275-276):

Em primeiro lugar foi atribuída ao CTE a tarefa de identificar relações entre medidas comerciais e ambientais com o objetivo de promover o desenvolvimento sustentável e, em segundo lugar, fazer recomendações apropriadas para que modificações fossem implementadas nas regras do sistema multilateral de comércio. Assim, com o intuito de fazer que o comércio internacional e políticas ambientais se tornassem mutuamente sustentáveis, ao CTE foi determinada a abordagem de alguns temas específicos, dentre os quais ressaltam-se:

- A relação entre provisões do sistema multilateral de comércio e medidas comerciais com propósitos ambientais, incluindo-se aquelas pertinentes a tratados multilaterais ambientais (TMAs);

- A relação entre políticas ambientais relevantes para o comércio e medidas ambientais com efeitos comerciais significantes e as provisões do sistema multilateral do comércio;

- A relação entre as provisões do sistema multilateral de comércio e:

c) cobranças ou taxas com propósitos ambientais;

d) exigências com propósitos ambientais relacionadas a produtos, incluindo padrões e regulamentações técnicas, embalagem, rotulagem e reciclagem. 
- A relação entre mecanismos de solução de controvérsias do sistema multilateral de comércio e aqueles de TMAs.

- Os efeitos de medidas ambientais para o acesso a mercados, especialmente em relação aos países em desenvolvimento, em particular em relação aos menos desenvolvidos, e os benefícios ambientais de remoção de restrições e distorções ao comércio.

- A questão da exportação de bens domesticamente proibidos.

A relevância dos temas propostos, contudo, não modifica os fundamentos da criação da OMC, qual seja - a liberalização do comércio mundial - nem é esta a intenção. O que se pretendeu com a criação do CTE foi a análise de "políticas ambientais que interfiram nas relações comerciais entre os membros” (CARDOSO, 2003, p. 277), o que já representa um avanço, porém distanciado dos ideais marcados pela proposta do desenvolvimento sustentável e que implica no "reconhecimento de que preocupações com o meio ambiente devem nortear todas as fases da atividade econômica, ou seja, produção, transporte, comércio e consumo" (CARDOSO, 2003, p. 277).

Apesar do respeito à política ambiental adotada pelos Estados, em consideração ao exercício da soberania dos países-membros, a OMC não deixa de expressar sua preocupação com a atuação estatal de seus membros em relação à questão. Tanto é verdade e expressiva a valorização dada ao tema ambiental pela OMC, que foi prevista a possibilidade de imposição de medidas constitutivas de barreiras ao livre comércio, no GATT 1994 a título de exceção à obrigação de não discriminação e "destinadas a proteger a vida ou a saúde de seres humanos, dos animais ou vegetais (Artigo XX (b)), bem como aquelas relativas à conservação de recursos naturais não-renováveis (Artigo XX (g)" (CRETELLA NETO, 2003, p. 421).

A multilateralidade da OMC, porém, padece de algumas limitações, dentre as quais se destaca o seu objetivo principal: liberalização comercial mediante a proteção ao livre comércio e a condição secundária da questão ambiental. Assim, mesmo reconhecida a sua importância, não se destaca a intenção de impor medidas de caráter supranacional em proteção ao meio ambiente. $\mathrm{O}$ fundamento é o respeito à soberania dos Estados-membros e às diferentes condições que se apresentam entre os países desenvolvidos e em desenvolvimento, pois podem resultar em evidente desvantagem competitiva destes em comparação com aqueles. 
Ana Maria de Oliveira Nusdeo confirma, ao destacar o artigo XX do GATT, a importância dada ao tema ambiental, contudo alerta para "o problema do conflito entre proteção ambiental e liberdade de comércio" (NUSDEO apud PIMENTEL, 2003, p. 18)1, por conta das diferenças econômicas existentes entre os países de maior desenvolvimento em relação aos chamados países subdesenvolvidos.

A influência da Sociedade Internacional - formada hoje pelos Estados soberanos e por organismos internacionais das mais diversas naturezas, objetivos e vocações - é cada vez mais evidente no conjunto de normas internas. A humanidade assimilou, ao longo de sua existência, os valores por ela considerados importantes para a realização de suas necessidades e anseios, tanto em termos individuais, quanto coletivamente. $\mathrm{O}$ jogo de interesses, as possibilidades diferentes de cada um dos atores globais e os antagonismos evidenciados demonstram o grau da evolução humana, que não deve ser medida como avanço ou retrocesso, mas como etapas importantes do seu percurso.

\section{UNIÃO EUROPÉIA}

O alto custo humano e econômico, decorrentes das duas guerras realizadas na primeira metade do século XX, foi arrasador para o chamado velho mundo, que entrou em uma era de declínio econômico e político. Reerguer-se das cinzas era o desejo comum dos povos que há pouco tempo haviam sido rivais.

A formação do bloco regional, inicialmente com apenas seis Estados França, Alemanha, Itália, Bélgica, Holanda e Luxemburgo - representou um novo percurso ao povo europeu, "rumo à solidariedade, com o intuito de resgatar o que há de mais importante no ser humano, que é justamente sua

\footnotetext{
1 A autora transcreve: 'Nos termos do Acordo do GATT, com as revisões realizadas em 1994, quando do acordo da $\mathrm{OMC}$, já exceções à obrigação geral de não discriminação estabelecidas pelo acordo no artigo XX, que assim dispõe: Desde que as medidas não sejam aplicadas de forma a constituir quer um meio de discriminação arbitrária, ou injustificada, entre os países onde existem as mesmas condições, quer uma restrição disfarçada ao comércio internacional, disposição alguma do presente capítulo será interpretada como impedindo a adoção ou aplicação, por qualquer parte contratante, das medidas:

a) necessárias à proteção da moralidade pública;

b) necessárias à proteção da saúde e da vida das pessoas e dos animais e à preservação dos vegetais...

c) impostas para a proteção de tesouros nacionais de valor artístico, histórico ou arqueológico; [...]

g) relativas à conservação dos recursos naturais esgotáveis, se tais medidas forem aplicadas em conjunto com restrições à produção e ao consumo nacionais.'
} 
visão de humanidade, para que possa alcançar instituições e práticas governamentais mais abertas e mais justas" CACHAPUZ, 2004, p. 158). Vencedores e perdedores sofreram com os prejuízos e a destruição causadas pelas novas armas e pelo longo tempo de embate bélico.

O pavor de uma III Guerra foi determinante para a integração européia e a pedra fundamental da união entre países europeus deu-se em 9 de maio de 1950, no salão do Relógio do Quai d'Orsay, em Paris, onde o então ministro das Relações Exteriores francês Robert Schuman torna pública uma declaração que continha um plano preparado por Jean Monnet, cujo objetivo consistia em pôr em comum o controle dos recursos da França e da Alemanha nos domínios do carvão e do aço, duas economias fortes de então, com o objetivo de lançar as bases de uma paz duradoura na Europa. Assim surge a Comunidade Européia do Carvão e do Aço (CECA), através do Tratado de Paris, assinado em 18 de abril de 1951, entrando em vigor em 23 de julho de 1952, com a adesão da França, Alemanha, Itália, e os países do Benelux (Bélgica, Holanda e Luxemburo) (ACCIOLY, 2002, p. 56).

Após a assinatura do Tratado de Paris em 1951, somente em 1957 é que foram assinados dois outros acordos. O Tratado de Roma ou o Tratado Institutivo da Comunidade Econômica Européia - CEE - e o Tratado Institutivo da Comunidade Européia de Energia Atômica EURATOM ou CEEA. O primeiro tinha por objetivo "a criação de um a política econômica comum que permitisse a expansão contínua, uma estabilidade crescente e um aumento acelerado do nível de vida", e o segundo objetivava a promoção de utilização de "energia nuclear para fins pacíficos" (ACCIOLY, 2002, p. 57).

Ao longo do tempo, outros países europeus foram aderindo à proposta integracionista até que, em novembro de 1993, passa a vigorar um novo tratado que estabelece a União Européia, o chamado Tratado da União Européia ou Tratado de Maastricht, com o objetivo de atingir "outro degrau integracionista", sendo que "o avanço mais evidente é o da instauração progressiva de uma união monetária, com a consolidação de uma moeda única. A união social e política, com a instituição de uma cidadania da União e de uma política de defesa comum" (ACCIOLY, 2002, p. 58).

O que se verificou, a partir da União Européia, desde a sua instituição, foi a vontade política, oriunda do verdadeiro e intenso 
terror dos povos europeus com a possibilidade da deflagração de uma terceira e talvez derradeira guerra. Embora sua vocação seja em bases econômicas a paz foi o elemento de consolidação do bloco regional. Assim, a regionalização tornou-se uma realidade e "no caso da Comunidade Econômica Européia; a utilização das normas emanadas do Direito Comunitário e por isso auto executáveis, são nos dias de hoje uma realidade" (MUNIZ apud SILVA, 2002, p. 287).

A proteção ambiental, via sistema normativo supranacional, porém, não foi preocupação da comunidade européia, desde o início de sua regionalização, mediante seus três tratados originários - CECA, EURATOM e CEE. Somente em 1967, com a "Diretiva 67/548 que tratava da classificação e embalagem de substâncias perigosas e em 1970 as Diretivas 70/157 e 70/220 que trataram sobre os níveis de ruídos e a emissão de gases contaminantes por veículos a motor" (FREITAS JUNIOR, 2004 p. 1), respectivamente, é que se verificou a importância que o bloco regional europeu começou a imprimir à ação de proteção ao meio ambiente.

Em 1972, com a consolidação do processo de união econômica, foi assinada a Declaração de Chefe de Estados e de Governo na qual ficou confirmada a preocupação por novos valores, dentre os quais a proteção ao meio ambiente. Naquele mesmo ano, foi aprovado o Primeiro Programa de Meio Ambiente:

Onde se afirmava a necessidade do desenvolvimento de uma política ambiental comunitária, que declarava em seus pontos 1 e 2 que: conforme el artículo 2 del Tratado, es tarea de la CEE promover em la Comunidad um desarrollo armonioso de actividades econômicas i uma expansión continua y equilibrada, que ahora no puede imaginarse com ausência de uma campaña efectiva para combatir la polución y de uma mejora em la calidad de vida y la proteccíon Del médio ambiente (FREITAS JUNIOR, 2004, p. 1).

Vários documentos normativos introduziram diretrizes relativas à preservação ambiental, até que, em 2003, entrou em vigor o Tratado de Nice que alterou a forma, não o conteúdo de alguns dos artigos do Tratado de Amsterdam, firmado em 1997, que estabelecia dispositivos fundamentais de proteção ambiental.

Nesse Tratado, foram determinados como "objetivos do bloco o desenvolvimento harmonioso equilibrado e sustentável, ademais de um alto nível de proteção e melhora da qualidade do meio ambiente" 
(FREITAS JUNIOR, 2004, p. 3). ${ }^{2} \mathrm{O}$ conteúdo do artigo $3^{\underline{a}}$ do mesmo diploma determina:

a criação de uma política ambiental com o objetivo de alcançar um nível de proteção elevado, considerando a diversidade de situações existentes nas diversas regiões do território da Comunidade, e tendo como base os princípios de cautela, de prevenção, de correção dos atentados ambientais preferentemente na fonte mesma, e o princípio do contaminador pagador 9 FREITAS JUNIOR, 2004, p. 4).

Os conflitos decorrentes do descumprimento ou da interpretação inadequada dos Tratados e Diretivas são dirimidos pelo Tribunal de Justiça da Comunidade Européia, e, segundo afirma Ana Maria de Oliveira Nusdeo ao apresentar o caso das embalagens de cervejas e refrigerantes, no qual a Comissão da Comunidade moveu ação contra a Dinamarca:

A partir de tal raciocínio o tribunal reiterou o entendimento em caso precedente no sentido de ser a proteção ambiental um dos objetivos essenciais da Comunidade, apto a justificar limitações do princípio da liberdade de circulação de mercadorias e entendeu que a obrigatoriedade de coleta para reutilização de embalagens era medida justificável relativa à proteção do meio ambiente.

[...] Pode-se destacar, assim, ainda que de forma extremamente sintética, os elementos principais do posicionamento do Tribunal: 1) a proteção ambiental é um dos objetivos essenciais da Comunidade; 2) pode ser aceita imposição de obstáculos à livre circulação de mercadorias em resultado de diferenças nas legislações nacionais desde que sejam reconhecidas como necessárias ao cumprimento de exigências do próprio direito comunitário; 3) sejam aplicáveis a produtos domésticos e importados sem distinção e 4) sejam proporcionais aos objetivos de proteção ambiental a que se propõe (NUSDEO apud PIMENTEL, 2003, p. 16).

2 Esclarece o autor: Com a aprovação do Ato Único Europeu - AUE, em dezembro de 1986 e com vigência a partir de $1^{\underline{a}}$ de julho de 1987, introduziu-se de maneira explicita a política ambiental comunitária (...) Por fim o Tribunal de Justiça das Comunidades Européias sentenciou estabelecendo o meio ambiente como interesse ou valor atendível juridicamente como limite ao comércio intercomunitário. 
Observa-se que, no conjunto de elementos destacados, encontra-se delineada a proposição de desenvolvimento sustentável, pois sem desprezar aspectos de natureza comercial e econômica - objetivos específicos da existência do bloco regional - valoriza-se, de forma incontestável, a preservação do meio ambiente.

\section{MERCOSUL}

Exemplo de integração regional que exerceu influência sobre o tratamento da questão ambiental regional está na criação do Mercado Comum do Sul MERCOSUL, mediante a assinatura do Tratado de Assunção na data de 26 de março de 1991. Para Assis de Almeida (2001, p. 9), representou um "acordo-marco", vez que estabeleceu mecanismos destinados à formação de uma zona de livre comércio e união aduaneira entre a Argentina, o Brasil, o Paraguai e o Uruguai.

Norteando o processo de integração, foram estabelecidas suas necessidades essenciais, dentre as quais se destaca o desenvolvimento econômico com justiça social, a ser alcançado mediante a criação de meios para ampliar as dimensões do mercado de todos os signatários.

Vale, porém, ressaltar que o ideal integracionista dos países que compõem o MERCOSUL, data de muito antes da sua efetiva formação, pelo viés ambiental. Segundo a lição de Edis Milaré:

Desde os anos 50 do século passado, com os estudos pioneiros sobre o aproveitamento da Bacia Hidrográfica Paraná-Paraguai, conduzidos pelo cientista e pesquisador francês Joseph Lebret, esboçou-se e cresceu a perspectiva de um planejamento regional integrado, visando a maximizar os numerosos recursos que se concentram nesta vasta área, de interesse dos quatro países. A geopolítica veio conduzindo paulatinamente os países limítrofes a encararem a formação do que, hoje, se designa como "bloco regional", a exemplo de outras uniões ou grupos de países em diferentes partes do globo (2005, p. 1041).

O bloco se consolidou em 1991 e para alcançar os objetivos estabelecidos no Tratado, em seu preâmbulo, são ressaltados diversos aspectos. Com maior relevo, destaca-se a eficácia no aproveitamento dos recursos disponíveis e a preservação ambiental, embora não tenham sido estabelecidas naquele diploma, normas específicas de proteção ao meio ambiente regional.

As discussões relativas ao tema meio ambiente no MERCOSUL vêm evoluindo para uma abordagem mais ampla e consistente com as atuais demandas de um mundo globalizado. A rigor, os países signatários buscam 
o desenvolvimento segundo suas próprias necessidades, tendo como premissa a compatibilidade com o imperativo da preservação ambiental.

Antonio de Jesus da Rocha Freitas Junior afirma:

[...] não vamos encontrar normas de proteção ambiental no texto articulado do Tratado de Assunção. Não obstante, consideramos que a base jurídica para adotar normas ambientais está nos artigos $1^{\circ}$ e $5^{\circ}$ do Tratado, quando se trata da necessidade de coordenação das políticas macroeconômicas e setoriais que assegurem condições de concorrência entre os Estados-Membros, no marco do compromisso pactuado por estes para harmonizar as respectivas legislações nacionais naquelas áreas pertinentes, para fortalecer o processo de integração (2004, p. 2).

Cada um dos diversos Subgrupos de Trabalho do Grupo Mercado Comum, em consonância com o seu tema respectivo, ocupava-se da questão ambiental e, somente com a Declaração de Canela, firmada em 21 de fevereiro de 1992, ocorreu a incorporação da problemática ambiental em âmbito de Mercosul, consolidando uma posição conjunta dos países signatários, relativamente a:

proteção da atmosfera, diversidade biológica, a degradação dos solos, a desertificação, os bosques, os recursos hídricos, os assentamentos humanos, os recursos financeiros, o comércio internacional, o meio ambiente marinho, os resíduos perigosos e o fortalecimento institucional para o desenvolvimento sustentável (FREITAS JUNIOR, 2004, p. 2).

Em 26 e 27 de junho de 1992, realizou-se, em Las Leñas a II Reunião de Presidentes do MERCOSUL, quando se decidiu pela criação da Reunião Especializada em Meio Ambiente - REMA, com a função de analisar a legislação vigente em matéria do meio ambiente e propor aos Estados-Membros ações harmonizadas de proteção ao meio ambiente, "ressaltando o princípio de que a harmonização não significa estabelecer uma única legislação ambiental", mas "eliminar eventuais assimetrias e dirimir divergências" (FREITAS JUNIOR, 2004, p. 4) .

Nesse evento, foram estabelecidas medidas ambientais para os Subgrupos de Trabalho.

Com relação ao Sub-grupo de Trabalho $\mathrm{n}^{\circ} 7$ - Política Industrial e Tecnológica, se estabeleceu o ponto 3 , solicitando a harmonização 
nacional e provincial sobre o Meio Ambiente. Através da Resolução no 5/93, se criou a Comissão de Meio Ambiente no sub-grupo de Trabalho $n^{\circ} 7$ Política Industrial e Tecnológica.

No que se refere ao Sub-grupo de Trabalho no 8 - Política Agrícola, o item 7 tratava sobre a Sustentabilidade dos Recursos Naturais e Proteção Ambiental no Setor Agropecuário. Com relação ao Sub-grupo de Trabalho no 9 - Política Energética, o item 6, dispõe sobre a identificação de assimetrias na legislação e marco ambiental do setor energético (FREITAS JUNIOR, 2004, p. 3).

A partir da recomendação constante da Declaração de Taranco, assinada durante a Primeira Reunião de Ministros do Meio Ambiente do MERCOSUL, ocorrida nos dias 20 e 21 de junho de 1995, em Montevidéu (Uruguai), a Reunião Especializada de Meio Ambiente - REMA, foro de tratamento da temática ambiental no MERCOSUL, foi transformada no Subgrupo de Trabalho de Meio Ambiente (SGT - 6), subordinado ao Grupo Mercado Comum - GMC (MERCOSUL, 2004, p. 1), pela Resolução no 20/ 95, ratificada pela Decisão CMC no $59 / 00$.

Em 1995, a Resolução no 38 do Grupo Mercado Comum - GMC delimitou alguns objetivos essenciais, como ressalta Larissa Schimidt (apud PIMENTEL, 2004, p. 92):

- propostas de eliminação para restrições não tarifárias;

- inclusão do custo ambiental nos processos produtivos e adoção de ISO 14000;

- criação de uma base de dados com referência à tecnologias ambientais favoráveis;

- otimização de qualidade comum ambiental.

Visando ao cumprimento do plano de trabalho, aprovado pelo GMC, e as necessidades dele decorrentes, o SGT - 6 vem realizando reuniões ordinárias desde a sua criação, de modo que já efetuou, não sem enfrentar algumas dificuldades, negociações relativas ao Protocolo Adicional ao Tratado de Assunção onde se estabeleceram políticas públicas de conservação, turismo e proteção à saúde.

Embora tendo por objetivo a definição de alguns aspectos relacionados ao Protocolo, o SGT- 6, em reunião extraordinária, aprovou o Acordo Quadro sobre Meio Ambiente do MERCOSUL (2004).

Realizada em março de 2001, na cidade de Florianópolis, a reunião marcou as discussões pontuando áreas de fundamental importância, como gestão sustentável dos recursos naturais, qualidade de vida e planejamento ambiental, destacando as seguintes premissas básicas: 
- Ressaltar a necessidade de cooperar para a proteção do meio ambiente e para a utilização sustentável dos recursos naturais com vistas a alcançar a melhoria da qualidade de vida e o desenvolvimento econômico, social e ambiental sustentável;

- Estarem Convencidos dos benefícios da participação da sociedade civil na proteção do meio ambiente e na utilização sustentável dos recursos naturais.

- Reconhecer a importância da cooperação entre os Estados Partes com o objetivo de apoiar e promover a implementação de seus compromissos internacionais em matéria ambiental, observando a legislação e as políticas nacionais vigentes.

- Reafirmar os preceitos do desenvolvimento sustentável, preconizados na Agenda 21, adotada na Conferência das Nações Unidas sobre meio Ambiente e Desenvolvimento, em 1992.

- E Considerar que as políticas comerciais e ambientais devem complementar-se para assegurar o desenvolvimento sustentável dos recursos naturais dos Estados Partes (MERCOSUL, 2004, p. 1).

O capítulo II do Acordo-Quadro sobre o Meio Ambiente do MERCOSUL estabelece: "[...] é o objetivo, a proteção do meio ambiente e o desenvolvimento sustentável mediante a articulação entre as dimensões econômica, social e ambiental, contribuindo para uma melhor qualidade do meio ambiente e de vida das populações” (2004, p. 2).

Sobre o trabalho do SGT - 6 na condução dos esforços dispendidos em relação ao estabelecimento e implementação de políticas públicas, afirma Larissa Schimidt (apud PIMENTEL, 2001, p. 98):

Por fim, pode-se dizer que a condução das políticas ambientais do processo de integração do MERCOSUL encontra-se "num plano mais virtual" do que efetivo. Isto se deve certamente à falta de abertura e participação social nas negociações. Algumas formas de participação ocorrem, mas são ainda muito incipientes. Os considerandos do Tratado de Assunção, assim como quase todos os documentos emitidos pelo SGT-6, abordam o objetivo da qualidade de vida das populações dos países do MERCOSUL. A harmonização é meio para se obter tal fim, mas só a efetiva participação é que reforçará o processo, hoje tão carente de legitimação social.

Sem dúvida, o meio ambiente é um bem que deve ser tutelado de tal forma a permitir a preservação dos recursos naturais, esgotáveis ou 
não. O MERCOSUL incorporou algumas das premissas ambientais, embora não tenha angariado de forma unânime, posicionamentos favoráveis:

O texto do atual Acordo Ambiental foi muito estudado, surgindo grupos prós e contra. Aqueles que o exaltam, fundamentam sua argumentação na praticidade e objetivismo alcançado pelo dispositivo legal, permitindo a maior aplicabilidade deste. E os de posição contrária o consideram um retrocesso pelo seu pragmatismo, pois foram deixados de lado muitos direitos ambientais importantes que não deveriam ser excluídos (LOPES; BELICANTA, 2004, p. 7).

O Brasil incorporou em sua Constituição Federal a previsão dele desfrutar e o dever de protegê-lo. Trata-se de uma responsabilidade do Poder Público e de todos os cidadãos. Os demais países que compõem o MERCOSUL destacam, também, previsões semelhantes, como a Argentina que, no artigo 41 de seu diploma constitucional, estabelece a responsabilidade do Estado e dos administrados no que se refere à utilização racional dos recursos naturais.

Explica Alejando Altamirano que tal responsabilidade diz respeito "Aos administrados porque lhes concede o direito de utilizar racionalmente dos recursos naturais [...]. Ao Estado porque deve velar pela proteção do mesmo [...]" (LOPES apud ALTAMIRANO, 2004, p. 92).

O MERCOSUL, por sua vez, vem demonstrando especial interesse pela problemática ambiental, contudo é ainda incipiente a atuação integracionista em prol do meio ambiente, especialmente em razão das legislações vigentes nos países signatários, que, apesar de certa convergência, não refletem a harmonização necessária ao tema.

As iniciativas mercosulinas como o Acordo-Quadro sobre Meio Ambiente do Mercosul, tem o compromisso declarado dos países membros do bloco de promoverem políticas comerciais e ambientais sustentáveis. O Brasil com o Decreto 5.208 de 17 de setembro de 2004, promulgou o diploma regional, internalizando as regras nele estabelecidas. Apesar desta iniciativa pouco se fez, até o momento, no sentido de ampliar e proceder a ações efetivas para alcançar e manter o desenvolvimento sustentável.

As normas do Mercosul não são de aplicação direta nos Estados-Membros, pois necessitam ser incorporadas aos respectivos ordenamentos jurídicos nacionais. De maneira que estas normas não são obrigatórias para os habitantes, senão para os Estados, que devem aplicar essa obrigatoriedade a seus cidadãos, através da incorporação destas a seus respectivos ordenamentos jurídicos (FREITAS JUNIOR, 2004, p. 8).

Ainda que previsto nas normas do bloco regional, 
verificamos que da legislação ambiental gerada a partir da estrutura institucional do Mercosul, encontramos Decisões e Resoluções que foram adotadas principalmente pela necessidade de harmonizar as distintas legislações ambientais dos Estados-Membros, e pela necessidade de coordenar políticas setoriais (FREITAS JUNIOR, 2004, p. 9).

Resta o conflito entre outros interesses. $\mathrm{O}$ equilíbrio entre a proteção ao meio ambiente e o desenvolvimento econômico ainda não foi encontrado. Afirma Miguel Angel Del Arco Torres:

O Desenvolvimento sustentável se baseia em um vínculo essencial de cooperação do ser humano para com seus semelhantes com respeito a suas atividades e as conseqüências que estas podem trazer ao meio ambiente. Dito vínculo de cooperação representa a solidariedade coletiva, conceito que rege a preservação do meio ambiente e serve de fundamento da atuação do Estado para intervir na tarefa (apud FREITAS JUNIOR, 2004, p. 304).

O evidente desequilíbrio, manifestado pelo ordenamento jurídico do MERCOSUL, é confirmado pela inexistência de harmonização entre as legislações, tanto na área do meio ambiente, onde a negligência na condução das políticas públicas é flagrante, como em outros segmentos como civil, tributário, penal.

\section{A HARMONIZAÇÃO LEGISLATIVA}

O campo de estudo do tema ambiental é vasto e o Direito se consolida como uma das áreas cujo interesse vem aumentando de forma gradativa, embora lentamente, ao longo das últimas décadas. Afirma Guido Fernando Silva Soares:

A proteção do meio ambiente, mediante normas jurídicas, seja nos ordenamentos internos, seja no Direito Internacional, é um assunto recentíssimo. O meio ambiente, entendido como um complexo dinâmico, composto de elementos vivos e não vivos, os quais sofrem substanciais modificações pela ação do homem, passou a interessar ao Direito, somente à medida que foi necessário disciplinar a ação humana e suas conseqüências prejudiciais à natureza e, por reflexo, à existência do próprio ser humano [...] (2002, p. 407). 
Trata-se de um interesse global, que transcende as fronteiras territoriais internas e externas. No campo do Direito Internacional, o autor entende que, como ciência normativa:

Claro está, portanto, que o Direito somente levará em consideração as alterações que ocorrem na natureza, tanto as benéficas, quanto as maléficas, à medida que resultarem de comportamentos humanos, decorrentes de uma vontade livre do ser humano. Na verdade, o Direito Internacional do Meio Ambiente regula aqueles aspectos relacionados ao meio ambiente que dependem, portanto, tãosomente da ação livre do homem (aqueles que implicam a escolha de valores conflitantes) e cuja regulamentação ultrapassa o interesse de um único Estado (SOARES, 2002, p. 406).

Cada país com sua legislação específica, observa o constante descumprimento de regras existentes para a proteção de todos. Além disto, há interesses nacionais que se chocam com interesses externos. Afirma Edis Milaré:

Não há como desconhecer as ingentes dificuldades que amarram, de mil maneiras, a implantação legal de uma ordem internacional para o meio ambiente. Além dos inúmeros conflitos de interesse nas esferas pública e privada - que por si só explicam os impasses que fecham o caminho a governos, a organizações da sociedade civil e a grupo de cidadãos comprometidos com a qualidade ambiental -, o estatuto da soberania dos Estados-nação constitui-se em grande empecilho a uma legislação de caráter inter ou supranacional para a defesa do meio ambiente, em âmbito planetário e em outros âmbitos menores, até mesmo nas relações bilaterais (2005, p. 1049).

Em termos de regionalização, a proposta mais adequada para interferência no modelo instalado, segundo a doutrina dominante é a de harmonização legislativa. Em blocos regionais, como no caso do MERCOSUL, é imprescindível oferecer maior contribuição no sentido de imprimir uma nova dinâmica legislativa a fim de obter resultados mais substanciais.

Nesse aspecto, ressalta Alejandro Altamirano a dificuldade da aplicação dentro de cada Estado, do "ecotributo na relação entre os países membros do processo de integração econômica":

[...] no caso do nosso país o Mercosul, devido ao tratamento discriminatório que se produziria sobre a livre transferência de bens, entre produtos nacionais e importados. Desta forma pode ser desvirtuado o critério de harmonização que é um dos pilares de todo processo de integração (apud. LOPES, 2004, p. 56). 
As doutrinas nacional e estrangeira enfatizam a importância da harmonização legislativa, para alcançar de forma mais rápida e adequada o equilíbrio das relações econômicas regionais. Trata-se de uma das mais substanciais condições para o sucesso da regionalização.

Exemplo de tal entendimento é a lição de Maria de Fátima Ribeiro, em especial para questões de natureza tributária, e que acaba por se coadunar, também, às peculiaridades da legislação ambiental:

Vale a pena ressaltar que a harmonização tributária não significa equalização total de alíquotas e bases tributárias em vários países e em todos os tributos. O que se pretende é obter um mercado globalizado que seja consistente com o menor grau possível de distorções. Nesse sentido, há necessidade de aproximar a legislação tributária pertinente entre todos os países membros do MERCOSUL (2001, p. 1).

O projeto ambiental não está restrito a um país ou a um bloco econômico específico. Exige a conscientização de todos os povos, por diversas razões, das quais se destaca o desastre ecológico, ou o dano ambiental e seus prejuízos e conseqüências que não se atém às fronteiras dos Estados. Afetar o meio ambiente é desconhecer do dano à extensão geográfica, de quem e quantos são por ele atingidos, bem como o tamanho do prejuízo. Para Guido Fernando Silva Soares:

Por sua própria natureza, certos fenômenos biológicos ou físicos localizados dentro de um espaço geográfico submetido à soberania de um Estado exigem regulamentação internacional, seja porque, em sua unicidade, estendem-se sobre a geografia política de vários países, seja porque os fenômenos a serem regulados somente poderão sê-lo com a intervenção de normas internacionais (2002, p. 406).

Ressaltando a importância da atitude preservacionista da Sociedade Internacional, contudo, alerta Alejando Altamiro que:

A partir de uma perspectiva supranacional, quando se cria um "ecotributo" para resolver um problema local se gera uma diminuição na produção do bem. Tal circunstância pode afetar diretamente a competitividade internacional, regional ou global, conseqüentemente se altera a relação custo benefício.

É por ele que estes problemas são atacados mediante a harmonização de políticas de transcendência internacional. Este princípio foi estabelecido 
no Princípio 16 da Declaração do Rio sobre Desenvolvimento e Meio ambiente, estabelecendo que as autoridades nacionais devem promover o uso de instrumentos econômicos em relação com seus interesses públicos sem distorcer o comércio e as inversões internacionais (apud. LOPES, 2004, p. 57).

Em termos de bloco regional, como o MERCOSUL, a integração é, na atualidade, o caminho para o desenvolvimento, segundo os parâmetros de globalização. No entanto, a sustentabilidade do desenvolvimento certamente se consubstancia mediante a cooperação entre os Estados em todos os aspectos, sendo o meio ambiente um dos mais relevantes.

O MERCOSUL reflete a tendência mundial, que pressupõe um tratamento coeso e sem privilégios entre as nações desenvolvidas e em desenvolvimento, sem deixar de levar em consideração as diferenças econômicas, sociais, culturais, científicas, tecnológicas e políticas, e que devem se traduzir em estímulo à busca ininterrupta por novas alternativas ao desenvolvimento sustentável e a manutenção da vida humana na Terra.

O Bloco do Sul também comunga do ideal de que todos devem imprimir o máximo de esforços no sentido de preservação do meio ambiente. Desta forma, seria possível garantir à atual geração e às futuras uma qualidade de vida sadia, tendo sempre em vista o desenvolvimento econômico que é, também, considerado na perspectiva capitalista, uma das condições fundamentais para uma sobrevivência digna.

O sistema jurídico, instituído pela integração regional e pelos Estados, deve sua força e coesão aos princípios jurídicos que regem a totalidade do Direito, o que não o protege das mazelas decorrentes do conflito de leis, o descumprimento, as lacunas, os interesses antagônicos. As dificuldades não se apresentam apenas à questão ambiental, mas também no que tange a outras matérias e interesses.

O desenvolvimento econômico sustentável representa um ideal que remete à busca de alternativas para a preservação do meio ambiente com justiça social. Neste conjunto de fatores, a harmonização das legislações interna e internacional e a sua convergência, são condição sine qua non ao desenvolvimento científico, tecnológico, educacional, cultural, social, político e econômico.

\section{CONCLUSÃO}

A regionalização e globalização são expressões que se incorporaram ao cotidiano atual. Expressam processos eminentemente econômicos, que produzem reflexos em conceitos jurídicos e políticos, há muito estabelecidos. 
Os interesses e necessidades da sociedade internacional, explicitados em Tratados e Acordos internacionais são incorporados pelos Estados que, sob a influência de tais instrumentos, cedem parcela de sua soberania na busca de vantagens globais como desenvolvimento econômico e social, progresso cultural e tecnológico e proteção ao meio ambiente.

$\mathrm{Na}$ rede de relações regionais e globais estabelecidas no panorama internacional, as tábuas axiológicas são permeadas por uma concepção de que a acumulação de capital é o modo para alcançar a satisfação pessoal. Infere-se daí a idéia de que o crescimento econômico possa ser sinônimo de qualidade de vida. Esta percepção, própria do modelo capitalista enraizado nos ideais do liberalismo econômico, se contrapõe à concepção de universalização do desenvolvimento sócio-econômico sustentável. Tais constatações são possíveis face aos registros de compromissos internacionais que consolidaram acordos internacionais e comunitários nas últimas décadas. A sustentabilidade do desenvolvimento sócio-econômico mundial está ainda em segundo plano.

São tímidas as iniciativas internacionais no sentido de uma harmonização legislativa em torno das questões ambientais, embora, se reconheça que seja este o único percurso para deflagrar, ainda que tardio, o desenvolvimento econômico com preservação ambiental e justiça social.

As mudanças necessárias diante das externalidades ambientais negativas tardam a acontecer. Não há um foro democrático internacional suficientemente reconhecido para impor a todos Estados soberanos os valores ambientais. Para sua internalização dependem da sensibilidade política e de mudança de mentalidade. Sob aspecto jurídico seriam possível pelo processo da harmonização legislativa.

Alguns países desenvolvidos atribuem aos países subdesenvolvidos o ônus da preservação ambiental, mas, somente após terem alcançado um grau de desenvolvimento ao preço de grave e irrecuperável degradação.

Assim, as responsabilidades pelo desenvolvimento econômico sustentável, continuam em discussão, sem a visão de que o que está é jogo é a sobrevivência da raça humana. A esperança é de que a natureza, na sua infinita sabedoria, continue praticando os valores do perdão e da paciência. 


\section{REFERÊNCIAS}

ACCIOLY, E. Mercosul \& União Européia - Estrutura jurídico-institucional. 2. ed. Curitiba: Juruá. 2002.

ALMEIDA, J. G. A. MERCOSUL: Manual de direito da integração. Rio de Janeiro: Lúmen Júris. 2001.

ALTAMIRANO, A. In: LOPES, F. A. M. Estudo da evolução do tratamento ambiental no Mercosul: do Tratado de Assunção até o Acordo Quadro sobre Meio Ambiente. (Trad. Livre). Disponível em: <www.Jus navigandi.com.br>. Acesso em: jul./2004

CACHAPUZ, R. R. Direito Comunitário na União Européia. In: SOARES, M. A. S. Revista Jurídicada UNIFIL. Londrina, p 158. 2004.

CARDOSO, S.A. Comércio e meio ambiente. In: BARRAL, W. (Org.) O Brasil e a OMC. 2. ed. Curitiba: Juruá, 2003.

CRETELLA NETO, J. Direito Processual na Organização Mundial do Comércio - OMC: Casuística de interesses para o Brasil. São Paulo: Forense, 2003

FREITAS JUNIOR, A. J. R. A proteção ambiental na União Européia. Disponível em: 〈www.jusnavigandi.com.br〉. Acesso em jul./2004.

Considerações acerca do Direito Ambiental do Mercosul. Disponível em: <WWW.jusnavigandi.com.br>. Acesso em jul./2004.

LOPES, F. A. M.; BELICANTA, F. C. Estudo da Evolução do tratamento ambiental no Mercosul: do Tratado de Assumção até o Acordo Quadro sobre Meio Ambiente. Disponível em: www.jusnavigandi.com.br. Acesso em: jul/2004.

MERCOSUL/SGT-6. Resumo Histórico. Disponível em: 〈www.mma.gov.br〉. Acesso em: abr./2004

MILARÉ, É. Direito do Ambiente. São Paulo: Revista dos Tribunais. 2005

MUNIZ, D. L. L.; PINHEIRO, A. C. D. Direito Comunitário - O crime tributário Internacional: propostas e possibilidades em âmbito de Mercosul. In: SILVA, O. V. Os novos desafios do Direito, comércio e relações internacionais no século XXXI, p. 287. ENCONTRO DE ESTUDANTES DE DIREITO DO MERCOSUL. 10. Londrina: UNIFIL, 2002.

NUSDEO, A. M. O. Comércio internacional não discriminatório e proteção ambiental. In: PIMENTEL, L. O. Direito internacional e da Integração, p. 18. Florianópolis: Fundação Boiteux, 2003.

RIBEIRO, M. F. Considerações sobre a supremacia dos tratados internacionais sobre a legislação brasileira: O caso do MERCOSUL. Disponível em: <www.jus navigandi.com.br>. Acesso em: dezembro/2001. 
SCHIMIDT, L. Panorama da Legislação ambiental do mercosul sob a ótica comparada dos princípios ambientais europeus. In: PIMENTEL, L. O. Mercosul, Alca e Integração Euro-Latino Americana. v. 2, p. 92. Curitiba: Juruá, 2001.

SOARES, G. F. S. Curso de Direito Internacional Público, v. 1. São Paulo: Atlas, 2002

Torres, M. A. D. A. In: FREITAS JUNIOR, A. J. R. Considerações acerca do Direito Ambiental do Mercosul. p. 2. Disponível em: <www.jusnavigandi.com.br〉. Acesso em jul./2004. 
